\title{
Monte Carlo Programs and Other Utilities for High Energy Physics $\dagger$
}

\author{
Andrea P. T. Palounek \\ Physics Division \\ Lawrence Berkeley Laboratory \\ 1 Cyclotron Rond, Berkeley, CA $9 \$ 720$ \\ Saul Youssef \\ Supercomputer Computations Research Institute \\ Florida State University \\ Tallahassee, Florida 92906-4052
}

May 1990

\section{DISCLAIMER}

\begin{abstract}
This report was prepared as an
Government

employees, makes any warranty States Governmeat nor any an agency of the United States bility for the accuracy, completeneress or implied, or assumes agency thereof, nor any of their process disclosed, or represents eness, or usefulness or assumes any legal liability or responsi ence herein to any specific coms that its use would not infringermation, apparatus, product, or manufacturet, or otherwic commercial product, process, or ge privately owned rights, or mendation, or favoring by does not necessarily constitute or service by trade name, trademart and opinions of auth by the United States Govertitute or imply its endorseme, trademark, Uaited States of authors expressed herein Government or any agency torsement, recomStates Government or any agency thereor necessarily stale or thereof. The views
\end{abstract}

† This work was supported by the Director, Office of Energy Research, Office of High Energy and Nuclear Physics, Division of High Energy Physics, of the U. S. Department of Energy under Contracts No. DEAC03-76SF00098 and No. DE-FC,05-85ER250000. 


\title{
Monte Carlo Programs and Other Utilities for High Energy Physics
}

\author{
Andrea P. T. Palounek \\ APTP@LBL \\ Lawrence Berkeley Laboratory \\ 1 Cyclotron Road, Berkeley, CA 9 \$720 \\ Saul Youssef \\ SCRI::YOUSSEF \\ Supercomputer Computations Research Institute \\ Florida State University \\ Tallahassee, Florida 92906-4052
}

The Software Standards and Documentation Group of the Workshop on Physics and Detector Simulation for SSC Experiments has compiled a list of physics generators, detector simulations, and related programs. This is not meant to be an exhaustive compilation, nor is any judgement made about program quality; it is a starting point for a more complete bibliography. Where possible we have included an author and source for the code. References for most programs are in the final section.

\section{Contents}

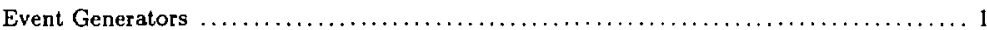

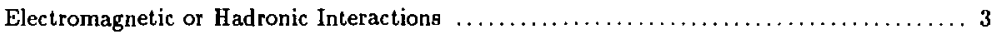

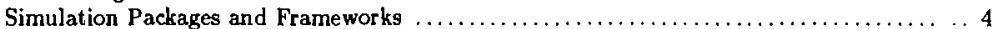

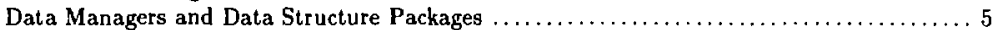

Display, Fitting, and Analysis Programs; Interactive Interfaces $\ldots \ldots \ldots \ldots \ldots \ldots \ldots \ldots \ldots$

Programming Aides, Source Code Managers, and Other Essentials $\ldots \ldots \ldots \ldots \ldots \ldots \ldots \ldots 7$

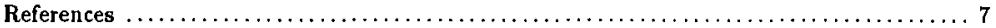

\section{Event Generators}

\begin{tabular}{|c|c|c|c|}
\hline Program & Author(s) & Contact & Description \\
\hline ARIADNE & $\begin{array}{l}\text { U. Pettersson and } \\
\text { L. Lönnblad }\end{array}$ & $\begin{array}{l}\text { KITTEL } \\
\text { @CERNVM }\end{array}$ & $\begin{array}{l}\text { A program for QCD cascades in the color dipole } \\
\text { formulation. }\end{array}$ \\
\hline BABAMC & $\begin{array}{l}\text { F. Berends } \\
\text { et al. }\end{array}$ & CERN & $\begin{array}{l}\text { Stand-alone first order generator for } e^{+} e^{-} \rightarrow \\
e^{+} e^{-}(\gamma) \text {. }\end{array}$ \\
\hline BHLUMI & $\begin{array}{l}\text { S. Jadach and } \\
\text { B. F. L. Ward }\end{array}$ & CERN & $\begin{array}{l}\text { Uses the YFS method to simulate multiple photon } \\
\text { effects in } e^{+} e^{-} \rightarrow e^{+} e^{-} n(\gamma) \text { at low angles, on an } \\
\text { event by event basis. }\end{array}$ \\
\hline CALASY & Z. Was & $\begin{array}{l}\text { WASM } \\
@ \text { CERNVM }\end{array}$ & $\begin{array}{l}\text { A semianalytical program for the calculation of ba- } \\
\text { sic observables of } r \text { decay products such as } \sigma_{t o t} \text {, } \\
A_{F B} \text {, and } \cos (\theta) * \text { energy distributions at LEP ener- } \\
\text { gies. }\end{array}$ \\
\hline CALTECH-II & $\begin{array}{l}\text { T.D. Gottschalk } \\
\text { (Cal Tech) }\end{array}$ & CalTech & $\begin{array}{l}\text { An } e^{+} e^{-} \text {event generator based on parton showers } \\
\text { and a hybrid of cluster ( } d \text { la Webber) and strıng } \\
\text { (à la Lund) hadronization. }\end{array}$ \\
\hline
\end{tabular}




\begin{tabular}{|c|c|c|}
\hline Program & Author(s) & Contact \\
\hline COJETS & $\begin{array}{l}\text { R. Odorico } \\
\text { (Bologna) }\end{array}$ & CERN \\
\hline DPSJET & W. Ochs & $\begin{array}{l}\text { WWO } \\
\text { @DMOMPI1] }\end{array}$ \\
\hline DTUJET & J. Ranft & CERN \\
\hline DYMU2 & $\begin{array}{l}\text { J. Campagne } \\
\text { R. Zitoun }\end{array}$ & CERN \\
\hline EPOCS & $\begin{array}{l}\text { K. Kato and } \\
\text { T. Munehisa }\end{array}$ & KEK \\
\hline EPOS & G. Valenti et al. & $\begin{array}{l}\text { GIANNI } \\
\text { @VXCERN }\end{array}$ \\
\hline EURODEC & $\begin{array}{l}\text { A. Ali and } \\
\text { B. van Eijk }\end{array}$ & CERN \\
\hline EXPOSTAR & $\begin{array}{l}\text { D. Kennedy } \\
\text { et al. }\end{array}$ & SLAC \\
\hline
\end{tabular}

FPAIR

F. Berends CERN et al.

G. Marchesini and CERN

B. Webber

HOWLEEG

CERN

ISAJET

F. Paige and

BNL

S. Protopopescu

PAIGE@BNL

JE'TSET

T. Sjöstrand et al. CERN

\begin{tabular}{|c|c|c|}
\hline KORALB & Z. Was & $\begin{array}{l}\text { WASM } \\
\text { @CERNVM }\end{array}$ \\
\hline KORALZ & Z. Was & $\begin{array}{l}\text { WASM } \\
\text { @CERNVM }\end{array}$ \\
\hline MMGE 92 & $\begin{array}{l}\text { J. P. Alexander } \\
\text { et al. }\end{array}$ & CERN \\
\hline MOE & $\begin{array}{l}\text { G. Bonvicini } \\
\text { et al. }\end{array}$ & CERN \\
\hline
\end{tabular}


Program

MULTJ

MUONMC

MUSTRAAL

NLLjet

NUNUBGG

OLDEAB

PAPAGENO

PARJET

PHOTOS

PYTHIA

RABHAT

SAGE

TEEGG

TIPTOP

UCLA

C. Buchanan and

S. Chun

B. van Eijk and

Z. Was

T. Sjöstrand and

H.-U, Bengtsson

K. Tobirnatsu and KEK

Y. Shimizu

R. Chaffee

SLAC

SLAC

S. J adach and

J, Kühn

JXK

@DMOMPI1

UCLA

UCLA:CDBP04

\section{Description}

A program for QCD event simulation in $e^{+} e^{-}$annibilation at LEP energies.

Sister program to BABAMC, simulates $e^{+} e^{-} \rightarrow$ $\mu^{+} \mu^{-}(\gamma)$.

Simulation of radiative corrections to the processes $e^{+} e^{-} \rightarrow \mu^{+} \mu^{-}$and $e^{+} e^{-} \rightarrow \bar{q} q$ in the $Z^{0}$ region.

A QCD parton shower Monte Carlo based on the next-to-leading log approximation, uses JETSET for hadronization.

Simulates and calculates the cross section for $\mathrm{e}^{+} \varepsilon^{-} \rightarrow \nu \bar{\nu} \gamma(\gamma)$.

A Bhabha event generator developed for PEP and PETRA energies.

A partonic Monte Carlo program that uses exact QCD matrix elements for given processes.

Implements the evolution of quark-antiquark jets as produced in $e^{+} e^{-}$.

Models bremsstrahlung photons in decays.

A general purpose hadron-hadron event generatnr that uses JETSET for hadronization.

An $e^{+} e^{-}$event generator with a missing final $e^{+}$ and/or $e^{-}$.

A simple and fast parton phase space Monte Carlo.

Simulates radiative Bhabha scattering up to $O\left(\alpha^{2}\right)$ for configurations when one or both electrons scatter at small angles.

Models heavy fermion production and decay in $e^{+} e^{-}$annihilation, incorporating initial state radiation, longitudinal beam polarization, and the effects of the polarizations of the produced heavy fermions.

An adaptation of JETSET which uses the Lund parton shower structure, but replaces the Lund fragmentation description with a small number of hadron level parameters.

A heavy ion event generator. 
CASIM

A. Van Ginneken FNAL

COG

EGS4

FLUKA

T. P. Wilcox and

LLNL

E. M. Lent

W. R. Nelson et al.
A. Aarnio et al.
CERN

GHEISHA

H. Fesefeldt

Aachen

HADRIN

K. Hlayssgen and

J. Ranft.

HETC

LAHET

R. G. Alsmiller, et al.

R. E. Prael and LANL

H. Lichtenstein

MARS

N. V. Mokhov and FNAL

J. D. Cossairt

MCNP

LANL

LEE@LAMPF

MORSE

M. B. Emmett

ORNL

NUCRIN

CERN

J. Ranft

Models hadronic production in hadran-nucleus collisions via a modification of the Hagedorn-Ranft thermodynamic model.

A neutron-photon transport code designed to solve the Boltzman equation for deep penetration (shielding) problems.

Simulates electromagnetic interactions with matter.

Sinsulates hadronic cascades, with an interface to EGS4 for electromagnetic interactions. The core event generator EVENTQ is also used in HETC.

Simulates hadronic inter actions, with an interface to EGS4 for electromagnetic interactions.

Simulates hadron-nucleon interactions up to about $5 \mathrm{GeV}$.

Simulates hadronic interactions with matter.

A union of the HETC code and MCNP with a common geometry and a few enhancements to HETC.

Simulates hadronic and electromagnetic cascades and $\mu$ transport.

LANL's continuous energy neutron-proton transport code. Simulates hadronic interactions below about $20 \mathrm{MeV}$.

Simulates low energy hadronic interactions.

Simulates low energy hadron-nucleus interactions.

Simulation packages and Frameworks
ANLSIM
H.-J. Trost
ANLHEP::TROS
A GEANT framework for SSC simulation.
CALOR89
T. Gabriel et al.
ORNL
A general simulation package for hadronic interac- tions; encompasses HETC and lower energy codes.
GARF
R. Veenhof
CERN

A program for the detail.d simulation of 2-D wire chambers consisting of thin wires and equipotential planes.

$\begin{array}{lll}\text { GEANT3 } & \text { R. Brun et al. } & \text { CERN } \\ \text { GEANE } & \text { M. Maire, } & \text { CERN } \\ & \text { E. Nagy } & \\ & \text { et al. } & \end{array}$

A general delector simulation package.

Calculates average trajectories of particles and calculates the transport matrix and error covariance matrix. Integrated into GEANT. 


\begin{tabular}{|c|c|c|c|}
\hline Program & Author(s) & Contact & Description \\
\hline GFLASH & $\begin{array}{l}\text { G. Grindhammer } \\
\text { et al. }\end{array}$ & $\begin{array}{l}\text { IJESY } \\
\text { (F36GGG } \\
\text { @DHIIDESY3) }\end{array}$ & $\begin{array}{l}\text { A package to add parametrised showers into } \\
\text { GEANT. }\end{array}$ \\
\hline GVerify & S. Youssef & SCRI::YOUSSEF & Detects errors in GEANT geometries. \\
\hline HERMES & D. Filges & $\begin{array}{l}\text { KFA Jülich } \\
\text { REW089@JUKF11 }\end{array}$ & $\begin{array}{l}\text { A general simulation package with emphasis on } \\
\text { neutrons, based on a low energy version of IIETC. }\end{array}$ \\
\hline $\mathrm{MC4}$ & S. Youssef & SCRI::YOUSSEF & $\begin{array}{l}\text { Ilas vectorised EM interactions in simple geome- } \\
\text { tries. }\end{array}$ \\
\hline POISSON & $\begin{array}{l}\text { R. Holsinger } \\
\text { C. Iselin }\end{array}$ & CERN & $\begin{array}{l}\text { A collection of programs for calculating n.9gne- } \\
\text { tostatic and electrostatic fields for magnet design } \\
\text { calculations. }\end{array}$ \\
\hline QFL & $\begin{array}{l}\text { J. Freeman } \\
\text { et al. }\end{array}$ & FNAL & A simple detector sinulation. \\
\hline SPICE & & $\begin{array}{l}\text { SPICE@CAD } \\
\text {.BERKELEY.EDU }\end{array}$ & A general purpose circuit simulation program. \\
\hline SSCANA & $\begin{array}{l}\text { E. Wang and } \\
\text { A. Bay }\end{array}$ & $\begin{array}{l}\text { LBL } \\
\text { (EMWP04@I,BL) }\end{array}$ & An integrated simulation package. \\
\hline SSCSIM & S. Linn & SCRI::LINN & A GEANT framework for SSC Simulation. \\
\hline
\end{tabular}

Data Managers and Data Structure Packages

\begin{tabular}{|c|c|c|c|}
\hline ADAMO & $\begin{array}{l}\text { P. Palazzi } \\
\text { et al. }\end{array}$ & $\begin{array}{l}\text { PALAZZI } \\
\text { @VXCERN }\end{array}$ & $\begin{array}{l}\text { A drita system for scientific programming basid on } \\
\text { the Entity-Relationship model. }\end{array}$ \\
\hline BOS & V. Blobel & DESY & A data structure manager. \\
\hline CHEETAH & $\begin{array}{l}\text { P. Kunz and } \\
\text { G. Word }\end{array}$ & $\begin{array}{l}\text { WORD } \\
\text { @SLACVM }\end{array}$ & $\begin{array}{l}\text { A data management package for C programs, } \\
\text { portable between VM, VMS, and UNIX. }\end{array}$ \\
\hline DUCS & $\begin{array}{l}\text { A. S. Johnson } \\
\text { et al. }\end{array}$ & $\begin{array}{l}\text { TONYJ } \\
\text { @SLACVM }\end{array}$ & $\begin{array}{l}\text { Automated code and documentation distribution } \\
\text { system for IBM and VMS. }\end{array}$ \\
\hline JAZELLE & $\begin{array}{l}\text { A. S. Johnson } \\
\text { et al. }\end{array}$ & $\begin{array}{l}\text { TONYJ } \\
\text { @SLACVM }\end{array}$ & $\begin{array}{l}\text { A symbolic data management system for HEP data } \\
\text { from data acquisition to DST. }\end{array}$ \\
\hline TYPES & S. Youssef & SCRI::YOUSSEF & A data abstraction package for FORTRAN. \\
\hline UFMULI & $\begin{array}{l}\text { P. Avery } \\
\text { et al. }\end{array}$ & $\mathrm{U}$ of Florida & $\begin{array}{l}\text { A framework for HEP farm processing on VMS or } \\
\text { UNIX. }\end{array}$ \\
\hline YBOS & D. Quarrie & CDF, CEBAF & A data structure manager. \\
\hline ZEBRA & $\begin{array}{l}\text { R. Brun } \\
\text { et al. }\end{array}$ & CERN & A data structure manager. \\
\hline
\end{tabular}

\section{Display, Fitting, and Analysis Programs; Interactive Interfaces}

$\begin{array}{llll}\text { BWGNEW } & \text { W. S. Lockman } & \begin{array}{l}\text { UCSC } \\ \text { BILLY@SLACVM }\end{array} & \begin{array}{l}\text { A package which performs log likelihood fits to } \\ \text { Breit-Wigner and gaussian distributions using the } \\ \text { minimization routine MINUIT. }\end{array} \\ \text { Clustering Toolbox } & \text { S. Youssef } & \text { SCR1:.YOUSSEF } & \begin{array}{l}\text { This is a toolbox for exploring clustering algo- } \\ \text { rithms. }\end{array}\end{array}$




\begin{tabular}{|c|c|c|c|}
\hline Program & Author(s) & Contect & Description \\
\hline DISPLAY & $\begin{array}{l}\text { H. L. Videau, } \\
\text { B. Gabioud } \\
\text { et. al. }\end{array}$ & $\begin{array}{l}\text { KOELLNER } \\
\text { @LBL }\end{array}$ & $\begin{array}{l}\text { An interactive package for the display and manipu- } \\
\text { lation of HBOOK histograms. }\end{array}$ \\
\hline GBOOK & T. Sjöstrand & LUND & $\begin{array}{l}\text { An HBOOK-compatible histogramming package in } \\
\text { stindard FORTRAN. }\end{array}$ \\
\hline GEP & $\begin{array}{l}\text { E. Bassler } \\
\text { et al. }\end{array}$ & $\begin{array}{l}\text { R02BAS } \\
\text { @DHHDESY3 }\end{array}$ & $\begin{array}{l}\text { A batch and interactive package for generation, } \\
\text { display, and manipulation of histograms, scatter } \\
\text { plots, and n-tuples. }\end{array}$ \\
\hline HANDYC & B. Mours & $\begin{array}{l}\text { PFKEB } \\
\text { @SLACVM }\end{array}$ & $\begin{array}{l}\text { A general purpose histogramming and plotting } \\
\text { package for C programs. }\end{array}$ \\
\hline HANDYPAK & A. Boyarski & SLAC & $\begin{array}{l}\text { A general purpose histogramıning and plotting } \\
\text { package. }\end{array}$ \\
\hline HBOOK & $\begin{array}{l}\text { R. Brun and } \\
\text { D. Lienart }\end{array}$ & CERN & A histogramming and plotting pacnage. \\
\hline HIGZ & $\begin{array}{l}\text { R. Bock } \\
\text { et al. }\end{array}$ & CERN & An interactive graphics interfare based on ZEBRA. \\
\hline HPLOT & $\begin{array}{l}\text { R. Brun and } \\
\text { N. Cremel Somon }\end{array}$ & CERN & $\begin{array}{l}\text { A FORTRAN-callable facility for producing } \\
\text { HBOOK output on graphic devices other than a } \\
\text { line printer. }\end{array}$ \\
\hline IDA & T. H. Burnett & SLAC & An interactive data analysis package. \\
\hline KUIP & $\begin{array}{l}\text { R. Brun and } \\
\text { P. Zanarini }\end{array}$ & CERN & $\begin{array}{l}\text { An interactive user interface frequently used in } \\
\text { CERN products. }\end{array}$ \\
\hline MINUIT & $\begin{array}{l}\text { F. James and } \\
\text { H. Roos }\end{array}$ & $\begin{array}{l}\text { CERN } \\
\text { VXCRNA::JAMES }\end{array}$ & $\begin{array}{l}\text { A tool to find the minimum value of a multi- } \\
\text { parameter function and analyse the shape of the } \\
\text { function around the minimum. }\end{array}$ \\
\hline MUDIFI & $\begin{array}{l}\text { R. Brun } \\
\text { et al. }\end{array}$ & CERN & $\begin{array}{l}\text { Multidimensional Fit program: allows user to ap- } \\
\text { proximate a linear combination of polynomials. }\end{array}$ \\
\hline PAW & $\begin{array}{l}\text { R. Brun } \\
\text { et al. }\end{array}$ & CERN & An interactive package for data analysis. \\
\hline PYKUIP & S. Linn & SCRI::LINN & PYKUIP is a KUIP interface to PYTHIA. \\
\hline REASON & $\begin{array}{l}\text { W. B. Atwood } \\
\text { et al. }\end{array}$ & $\begin{array}{l}\text { PFKEB@ } \\
\text { SLACVM }\end{array}$ & $\begin{array}{l}\text { A graphical physics analysis package for use in the } \\
\text { NextStep computing environment. }\end{array}$ \\
\hline TOPDRAWER & $\begin{array}{l}\text { R. Chaffee } \\
\text { (SLAC) }\end{array}$ & $\begin{array}{l}\text { many versions } \\
\text { CLEMENT } \\
\text { @RICE has a nice } \\
\text { interactive inter- } \\
\text { face }\end{array}$ & $\begin{array}{l}\text { Creates and manipulates good quality histograms } \\
\text { and plots. }\end{array}$ \\
\hline UGS & R. Beach & SLAC & $\begin{array}{l}\text { Unified Graphics System, a collection of FOR- } \\
\text { TRAN subroutines which is designed to run on a } \\
\text { number of computers and control almost any line } \\
\text { drawing graphic device. }\end{array}$ \\
\hline
\end{tabular}




\section{Frogramming Aides, Source Code Managers, Databases, and Other Essentials}

\begin{tabular}{|c|c|c|c|}
\hline ASPIRIN & A. S. Johnson & SLAC & $\begin{array}{l}\text { Provides partial translation from VAX FORTRAN } \\
\text { to FORTRAN77 (see also FORSE). }\end{array}$ \\
\hline CMZ & M. Brun et al. & CERN & $\begin{array}{l}\text { Code management using ZEBRA, compatible with } \\
\text { PATCHY. }\end{array}$ \\
\hline COMIS & $\begin{array}{l}\text { V. Berezhnoi } \\
\text { et al. }\end{array}$ & CERN & Compilation and Interpretation System. \\
\hline EXPAND & K. Chadwick & FNAL & $\begin{array}{l}\text { The CDF versin of VAX FORTRAN to IBM or } \\
\text { ACP FORIRAN. }\end{array}$ \\
\hline
\end{tabular}

FORSE S. Youssef

SCRI:YOUSSEF

Provides partial VAX FORTRAN to FORTRANTt (complementary to ASPIRIN).

FORTRIX

PATCIY R. Brun CERN

et al.

Translates FORTRAN to C.

A systcm for source code management. Being replaced by CMZ.

QSPIRES SLAC

A facility for using BITNET to search the SLAC high energy physics database or a variety of other databases with information such as names, phone numbers, and computer accounting information for people associated with SLAC.

SPIRES

installed ai SLAC: A general database for high energy physics, includand elsewhere ing preprints, papers, books, and conferences.

$\begin{array}{ll}\text { VMSREXX } & \text { A. S. Johnson } \\ \text { Tool al. } \\ \text { et } & \text { L. J. Osterweil } \\ & \text { et al. }\end{array}$

WHO
TONYJ OSLACVM

Numerical Algorithnss Group (312)971-2337

CERN and elsewhere
A REXX interpreter for VAX/VMS.

An integrated set of tools to support FORT P.AN software developrnent.

WHO is an interactive utility to find userids, nodes, and acidresses of high energy physicists.

\section{References}

For a general overview of $e^{+} e^{-}$generators, see

G. Altarelli, R. Kleiss and C. Verzegnassi, eds., "Z Physics at IEP1, Vol. 3: Event Generators and Software," CERN 89-08, Vol. 3, 1989, which includes

R. Kleiss (convener), D. Bardin, R. Barlow, A. Blondel, W. De Boer, G. Bonneaud, H. Burkhardt, J.L. Campagne, M. Dam, S. Jadach, D. Karlen, E.M. Locci, J. Ludwig, S. Van Der Marck, A.D. Schaile, V. Shchegelskii, L. Vertogradov, B.F.L. Ward. Z. Was, and R. Zitoun, "Monte Carlos for Electroweak Physics," and

T. Sjöstrand (convener), B.Bambah, J. Chrin, W. de Boer, J. Fuster, J. W. Gary, M. IHahn, V. Khoze, W. Kittel, B. Lampe, P. Mättig, T. Sjöstrand, H. Stone and B. van Eijk, "QCD generators," alcpublished as "QCD Generators for LEP," CERN-TII.5466/89 (1989). 
AEGIS, A. Van Ginneken, "AEGIS: A Program to Calculate the Average Behavior of Electromagnetic Showers," Fermilab Report FN-309 (1978); see also A. Van Ginneken, "Calculation of the Average Properties of Electromagnetic Cascades at High Energies (AEGIS)," Erice 1978, Proceedings, Computer Techniques In Radiation Transport and Dosimetry, (1978) 211-222.

ARIADNE, Leif Lönnblad, "ARIADNE: A Monte Carlo for QCD Cascades in the Color Dipole Formulation," LU-TP-88-5 (1988); see also Leif Lönnbiad and Ulf Pettersson, "ARIADNE: A Monte Carlo for QCD Cascades in the Color Dipole Formulation, an Update," LU-TP-88-15 (1988); Leif Lönnblad, "A Manual for ARIADNE Version 3," LU-TP-89-10 (1089); and CERN Yellow Report 89-08, vol. 3 (1989) p. 199.

BABAMC, F.A. Berends, R. Kleiss, and W. Hollik, "Radiative Corrections to Bhablha Scattering at High Energies. 2: Hard Photon Corrections and Monte Carlo Treatment," DESY Report 87/094 (1987), published in Nucl. Phys. B304 (1988) 712; see also M. Bohm, A. Denner, and W. Hollik, "Radiative Corrections to Bhabha Scattering at High Energies. 1. Virtual and Soft Photon Corrections," DESY Report 86/165 (1086), published in Nucl. Phys. B304 (1088) 687; and CERN Yellow Report 89-08, vol. $3(1989)$ p. 88.

BHLUMI, Stanislaw Jadach and B.F.L. Ward, "Multi-Photon Monte Carlo for Bhabha Scattering at Low Angles," University of Tennessee Report UTHEP-88-11-01 (1988), published in Phys. Rev. 40 (1989) 3582; see also CERN Yellow Report 89-08, vol. 3 (1989) p. 92.

BOS, V. Blobel, "The BOS System. Dynamic Memory Management," DESY Internal Report Number R188-01 (1988); see also V. Blobel, "The BOS System. Dynamic Memory Management. FORTRAN77 Version," DESY Internal Report Number F14-86-02 (1986).

BWGNEW, W. S. Lockman, "BWGNEW 2.1 User's Guide," Santa Cruz Institute for Particle Physics Report SCIPP 89/08 (1990).

CALASY, see CERN Yellow Report 89-08, vol. 3 (1989) p. 58.

CALOR89, T. A. Gabriel, J. E. Brau and B. L. Bishop, "The Physics of Compensating Calorimetry and the New CALOR89 Code System," Oak Ridge National Laboratory Report ORNL/TM-11060 (1989)

CALTECH-II, T. D. Gottschalk and D. A. Morris, "A New Model for Hadronization and $e^{+} e^{-}$Annihilation," Nucl. Phys. B288 (1987) 729; see also T. D. Gottschalk, "A Simple Phenomenological Model for Hadron Production from Low Mass Clusters," Nucl. Phys. B239 (1984) 325; and T. D. Gottschalk, "An Improved Description of Hadronization in the QCD Cluster Model for $e^{+} e^{-}$Annihilation," Nucl. Phys. B239 (1984) 349; see also CERN Yellow Report 89-08, vol. 3 (1989) p. 208.

CASIM, A. Van Ginneken, "CASIM: Program to Simulate Transport of Hadronic Cascades in Bulk Matter," Fermilab Report FN-272 (1975); see also A. Van Ginneken, "Calculation of the Average Properties of Hadronic Cascades at High Energies (CASIM)," Erice 1978, Froceedings, Computer Techniques In Radiation Transport and Dosimetry, (1978) 323.

CMZ, M. Brun, R. Brun and F. Rademakers, "CMZ - Code Management using ZEBRA," Proceedings of the Conference on Computing in High Energy Physics, Oxford, April 1989 (1989).

COG, T. P. Wilcox, Jr. and E. M. Lent, "COG: A Particle Transport Code Designed to Solve the Boltzman Equation for Deep-Penetration (Shielding) Problems-Volume I, Users Manual," Lawrence Livermore National Laboratory Report M-221-1. 
COJETS, R. Odorico, "COJETS: A Monte Carlo Simulation Program for $\ddot{p}-p$ and $p-p$ Collisions," Bologna University Report DFUB-88-27 (1989); see also R. Odorico, "COJETS: A Monte Carlo Program Simulating QCD in Hadronic Production of Jets and Heavy Flavors with Inclusion of Initial QCD Bremsstrahlung," Comp. Phys. Comm. 32 (1984) 139; and CERN Yellow Report 89-08, vol. 3 (1989) p. 215.

COMIS, V. Berezhnoi, R. Brun, S. Nitikin, X. Petrovykh and V. Sikolenko, "COMIS, Compilation and Interpretation System," CERN Program Library L210 (1988).

DPSJET, see CERN Yellow Report 89-08, vol. 3 (1989) p. 218.

DUCS, A. S. Johnson, B. Saitta, O. Gervasi, G. Bower, A. Rothenberg and A. Waite, "DUCS: A Fully Automated Code and Documentation Distribution System," SLAC-PUB-5230 (1990), Tresented ai Computing in Itigh Energy Physics Conf., Santa Fe, NM, Apr 9-13, 1990.

DYMU2, J. E. Campagne and R. Zitoun, "Electromagnetic Radiative Corrections at LEP-SLC Energies for Experimentalists," I.PNIEP'-88-08 (1988), published in Z. Phys. C43 (1989) 469.

EGS4, W. R. Nelson, H. Hirayama and D. W. O. Rogers, "The EGS4 Code System," Stanford Linear Accelerator Center Report SLAC-265 (1975); see also W. R. Nelson and Y. Namito, "The EGS4 Code System: Solution of Gamma Ray and Electron Transport Problems," SLAC-PUB-5193 (1990).

EPOCS, K. Kato and T. Munehisa, " $e^{\dagger} e^{-}$Event Generator EPOCS User's Manual" KEK Report 87-5 (1987).

EPOS, see CERN Yellow Report 89-08, vol. 3 (1989) p. 220.

i:URODEC, B. van Eijk, "EURODEC User Manual," DELPHI Report 89-39 PIIYS 41 PROG 136; see alsu B. van Eijk, "EURODEC Reference Manual," CERN DD Report in preparation; and CERN Yellow" Report 89-08, vol. 3 (1989) p. 226.

EXPOSTAR, D. Kennedy, B.W. Lynn, C.J.C. Im and R.G.Stuart, "Electroweak Cross Sections and Asynmetries at the $Z^{0}$," SLAC-PUB-4128 (1988), published in Nucl. Phys. B321 (1989) 83; see alm CERN Yellow Report 89-08, vol. 3 (1989) p. 53.

FLUKA, P. A. Aarnio, A. Fassò, J. Lindgren, J. Ranft and G. R. Stevenson, "Enhancements to thr F LUKA86 Program (FLUKA87)," CERN TIS-RP/190 (1987); see also P. A. Aarnio, A. Fassò, H-J. Miöiring, J. Ranft and G. R. Stevenson, "FLUKA86 User's Guide," CERN TIS-RP/168 (1986); sce also J. Ranft, H.J. Möhring, T.M. Jenkins, W.R. Nelson, "The Iladron Cascade Code, FI, UK A82: Setup and Coupling with EGS4 at SLAC," SLAC-TN-86-3 (1986).

FPAIR, see CERN Yellow Report 89-08, vol. 3 (1989) p. 81.

GEANT3, R. Brun, F. Bruyant, M. Maire, A. C. McPherson and P. Zanarini, "GEANT3," CERN Data Handling Division, DD/EE/84-1 (1987).

GEP, E. Bassler, "The Graphical Editor Program: GEP," Comput. Phys. Comm. 45 (1987) 201: see aiso E. Bassler, "GED - Graphical Editor Program for Presenting Physical Data, Version 1.0," DESY Internal Report DESY R02-81/02, revised version (1981).

GHEISHA, H. Fesefeldt, "The Simulation of Hadronic Showers: Physics and Applications," A achen Tech. Hochsch., III Phys. Inst. Report PITHA-85/02 (1985).

IIA DRIN, K. Hangssen and J. Ranft, "The Monte Carlo Code HADRIN to Simulate Inelast is IIad" Nucleon Interactions at Laboratory Energies Below 5 GeV," Comput. Phys. Comm. 39 (1986). 
HBOOK, R. Brun and D. Lienart, "HBOOK User Guide," CERN Program Library Y250 (1988); see also R. Brun and P. Palazzi "Graphical Presentation for Data Analysis in Particle Physics Experiments: THE HBOOK / HPLOT Package," CERN Data Handling Division Report CERN-DD/80/15 (1980).

HERMES, P.Cloth, D. Filges, R. D. Neef, Ch. Reul, G. Sterzenbach, B. Anders, H. Brückmann, T. W. Armstrong and B. Colborn, "HERMES," KFA-Report Jül-2203 (May 1988); see also B. Anders, P. Cloth, D. Filges, Ch. Reul and G. Sterzenbach, "Monte Carlo Simulation on Event-by-Event Base of Calorimeter Experiments with Uranium/Scintillator Layers Using the HERMES Code System," presented at the 3rd Topical Seminar on Pers sctives for Experimentad Apparatus at Future High Energy and Underground Laboratories, March 7-11, 1988, San Minitiato, Italy, Nucl. Instrum. Methods A277 (1989) 56; and ZEUS Calorimeter Group (F. Barreiro et al.), "Measurements of Longitudinal and Transverse Profiles for Hadron Showers in the Range $10 \mathrm{GeV}-100 \mathrm{GeV}$ and Comparisons with Monte Carlo Simulations," DESY Report. DESY 89/171 (1989).

IIERWIG, G. Marchesini and B.R. Webber, "HERWIG 3.0: A Monte Carlo Event Generator for Simulating Hadron Emission Reactions with Interfering Gluons," Cavendish-IIEP-88/7 (1988) and CavendishHEP-87/9 (1987); see also CERN Yellow Report 89-08, vol. 3 (1989) p. 235.

IIETC, R. E. Prael, "User's Guide to the IIETC Code System," Los Alamos National Laboratory Report Group X-6 (Bough Draft) (1985); see also R. G. Alsmiller, Jr., F. S. Alsmiller, T. A. Gabriel, and O. W. Hermann, "Modifications of the ITigh Energy 'Transport Code (IIETC) and Comparisons with Experimental Results," presented at the ANS Topical Conference on Theory and Practices in Radiation Protection and Shielding, 22-24 April 1987, Knoxville, Tennessee; and K. C. Chanaler and T. W. Armstrong, "Operating Instructions for the High-Energy Nucleon-Meson Transport Code HETC," Oak Ridge National Laboratory Report ORNL-4744 (1972).

HIGZ, R. Bock, R. Brun, O. Couet, R. Nierhaus, N. Cremel, C. Vandoni and P. Zanarini, "HIGZ - Iligh Level Interface to Graphics and ZEBRA," CFRN Program Library Q120 (1988).

HOWLEEG, see CERN Yellow Report 89-08, vol. 3 (1989) p. 91.

HPLOT, R. Brun and O. Couet, "HPLOT User Guide," CERN Program Library Y251 (1988); see also R Brun and P. Palazzi "Graphical Presentation for Data Analysis in Particle Physics Experiments: THE HBOOK / IIPLOT Package," CERN Data IIandling Division Report CERN-DD/80/15 (1980).

IDA, T. H. Burnett, "IDA: An Interactive Data Analysis Environment for High Energy Physics," Comput. Phys. Comm. 45 (1987) 195.

ISAJET, F. Paige and S. D. Protopopescu, "ISAJET - A Monte Carlo Generator for p-p and p-p Reactions," Brookhaven National Laboratory Report BNL 38034 (1986); see also F. Faige and S. D. Protopopescu, "ISAJET - A Monte Carlo Generator for $p$ - $p$ and $\bar{p}-\bar{p}$ Interactions," Sncwmass Summer Study 1986 (1986) 320 .

JAZELLE, A. S. Johnson, M. Breidenbach, If. Hissen, P. F. Kunz, D. Sherden and T. Eurnett, "JAZSLLE: An Enhanced Data Management System for High Energy Physics," SLAC-PUB-5231 (1990), Presented at 8th Computing in High Energy Physics Conf., Santa Fe, NM, Apr 9-13, 1990.

JETSET, T. Sjöstrand, "The LUND Monte Carlo for Jet Fragmentation and $e^{+} e^{-}$Physics: JETSET Vercion 6.2," Lund University Report LU-TP-85-1G (1985); see also T. Sjöstrand and M. Bengtsson, "The LUND Monte Carto for Jet Fragmentation and $e^{+} e^{-}$Physics: JETSET Version $0 . \hat{3}$ : an Update," Comput. Phys. Comm. 43 (1987) 367; and CERN Yellow Report 89-08, vol. 3 (1989) p. 255.

KORALZ, see CERN Yellow Report 89-08, vol. 3 (1989) p. 69. 
KUIP, ג. Brun and P. Zanarini, "KUIP - Kit for a User Interface Package," CERN Program Library i202 (1988).

LAHET, R. E. Prael and H. Lichtenstein, "User Guide to LCS: The LAHET code System," Los Alamos National Laboratory Report LA-UR-89-3014 (1989).

MARS, N. V. Mokhov, "The MARS10 Code Sygtem: Inclusive Simulation of Hadronic and Electromagnetic Cascades and Muon Transport, ${ }^{\prime}$ Fermilab National Laboratory Report FERMILAB-FN-509 (1989); see also N. V. Mokhoy and J. D. Cossairt, "A Short Review of Monte Carlo Badronic Cascade Calculations in the Multi-TeV Energy Region," Nucl. Instrum. Methods, A244, 349 (1986); and N. V. Mokhov, Soviet J. Particles and Nuclei (1987), 408.

MCNP, J. F. Briesmeister, "MCNP: A General Monte Carlo Code for Neutron and Photon Transport," Los Alamos National Laboratory Report LA-7396-M, Rev.2, (1986); see also W.L. Thompson, "MCNP: A General Monte Carlo Code for Neutron and Photon Transport: a Summary," Los Alamos National Laboratory Rerort LA-8176-MS (1979).

MINUIT, F. James and F. Roos, "MINUIT - Function Mimimization and Error Analysis," CERN Program Library D506 (I988); see also $\mathbf{F}$. J $\mathrm{J}^{3}$. nes, "MJNUIT - Interpretation of the Errors on Parameters," CERN Program Library D506-Supplement (1988); and F. James, "Determining the Statistical Signifitance of Experimental Results," CERN Yellow Report 81-03 and DD Report DD/81/02 (1981).

MMGE92, J. P. Alexander, G. Bonvicini, P. Drell and R. Frey, "Radjative Corrections to the $Z^{0}$ Resonance," SLAC-PUB-4376 (1987), published in Phys. Rev. D37 (1988) 56; see also CERN Yellow Report 89-08, vol. 3 (1989) p. 67.

MOE, G. Bon vicini and L. Trentadue, "An Inclusive and Exclusive Algorithm for QED Evolution," University of Michigan Preprint UM-1!E-80 39 (1988), published in Nucl. Phys. B323 (1989) 253; see also CERN Yellow Report $89-08$, vo! 3 (1939) p. 77.

MORSE, M. B. Emmett, "The MORSE Monte Carlo Radiation Transpurt Code System," Oak Ridge National Laboratory Report ORNL-4972 (1975); see also S. N. Cramer, "Applications Guide to the MORSE Monte Carlo Code," Oak Ridge Nationa! Laboratory Report ORNL/TM-9355 (1985); and A. Fasso, "The CERN Version of MORSE and its Application to Strong Attenuation Shielding Problems, CERN-TIS-RP/187/CF (1987).

MUDIFI, R. Brun, M. Hansroul, J. Kubler, P. Falazzi and Il. Wind, "MUDIFI - Multidimensional Fit Program," CERN DD Report DD/EE/80-l (1980).

MULTJ, R. Odorico, "A Monte Carlo Program for QCD Event Simulation in $e^{+} e^{-}$Annihilation at LEP Energies: Long Writeup," Bologna University Preprint IFUB 81/4 (1981), published in Comput. Phys. Commun. 24 (1981) 73; see also P. Mazzanti and R. Odorico "A Monte Cario Program for QCD Event Simulation in $e^{+} e^{-}$Annihilation at LEP Energies," Bologna University Preprint IFUB 80/13 (1980), published in Zeit. Phys. C7 (1980) 61.

MUONMC, see CERN Yellow Report 89-08, vol. 3 (1989) p. 66.

MUSTRAAL, F. A. Berends, R. Kleiss and S. Jadach, "Monte Carlo Simulation of Radiative Corrections to the Processes $e^{+} e^{--} \rightarrow \mu^{+} \mu^{-}$and $e^{+} e^{-} \rightarrow \bar{q} q$ in the $Z^{\sigma^{2}}$ Region," Comput. Phys. Commun. 29 (1983) 185. 
NLLjet, K.Kato, T. Munehisa, T. Kamae, A. Shirahashi, "Next-to-LL Parton Shower Generator for $e^{+} e^{-}$ Hadronic Annihilation - Description of the Program NLLjet," Note for NLLjet Version 0.1 March 31, 1989, Tokyo University Preprint Number UT-HE-89/01 (1989); see also Kiyoshi Kato and Tomo Munehisa, "QCD Parton Shower in $e^{+} e^{-}$Annihilation," KUDP-88/02 (1988), published in "Perspectives on Part. Phys.". Edited by S. Matsuda et al., World Scientific (1988); and CERN Yellow Report 89-08, vol. 3 (1989) p. 287.

NUCRIN, K. Hanssgen and J. Ranft, "The Monte Carlo Code NUCRIN to Simulate Inelastic HadronNucleus Interactions at Laboratory Energies Below 5 GeV," Comput. Phys. Comm. 39 (1986) 53; see also K. Hanssgen, R. Kirschner, J. Ranft and H. Wetzig, "Monte Carlo Simulation of Inelastic Iladron-Nucleus Reactions: Description of the Model and of the Computer Code NUCRIN," Kar] Marx University Report KMU-HEP-80-07 (1980).

NUNUBGG, F.A. Berends, G.J.H. Burgers, C. Mana, M. Martinez and W.L. van Neerven, "Rudiativ Corrections to the Process $e^{+} e^{-} \rightarrow \nu \bar{\nu} \gamma$," CERN-TII-4865/87 (1987), published in Nucl. Phys. B301 (1988) 583; see also A. Barroso, W. Beenakker, F.A. Berends, W. Blum, F. Boudjema, G.J. Burgers, H.H. Burkhardt, M. Caffo, J.P. Cole, N. Dombey, F. Dydak, J. Fleischer, E. Gonzales, W Hollik, S. Jadach, F. Jegerlehner, R. Kleiss, L. Lanceri, B.W. Lynn, C. Mana, M. Martinez, E. Neugebauer, D. Perret-Gallix, R. Ragazzon, P. Ratoff, J.C. Romao, J. Salicio, A. Shapira, E.

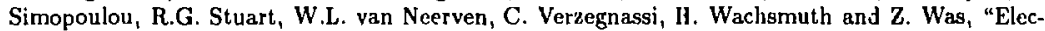
troweak Radiative Corrections at LEP Energies," CERN-EP/87-70 (1987), published in Aacien ECFA Workshop 1986:157; C. Mana, M. Martinez and F. Cornet, "Ilard Photon Corrections to the Process $e^{+} e^{-} \rightarrow \nu \bar{\nu} \gamma$," DESY Report 86/114 (1986); G. Mana and M. Martinez "On the Radiative Bhabha Scaltering for the single Photon Configuration," DESY Report 86/062 (1986), published in Nucl. Phys. B287 (1987) 601; and CERN Yellow Report 89-08, vol. 3 (1989) p. 83.

OLDBAB, F.A. Berends and R. Kleiss, "Distributions in the Process $e^{+} e^{-} \rightarrow e^{+} e^{-}(\gamma)$," Leiden University Preprint 83-0779 (1983), published in Nucl. Phys. B228 (9183) 537; see also CERN Yellow Report $89-08$, vol. 3 (1989) p. 86.

PARJET, S. Ritter, "Monte Carlo Code PARJET to simulate $e^{+} e^{-}$Annihilation Events via QCD Jets," Karl Marx University Report KMU-HEP-83-03 (1983), published in Comput. Phys. Comm. 31 (1984) 401; see also CERN Yellow Report 89-08, vol. 3 (1989) p. 291.

PATCHY, H. J. Klein and J. Zoll, "PATCIYY Reference Manual," CERN Program Library L400 (1988).

PAW, R. Brun, O. Couet, C. Vandoni and P. Zanarini, "PAW - Physics Analysis Workstation," CERN Program Library Q121 (1989); see also R. Brun, O. Couet, C. E. Vandoni and P. Zanarini "PAW: A General Purpose Portable Software Tool for Data Analysis and Presentation," CERN Data Handling Division Report CERN-DD/89/17 (1989) and Proceedings of the Conference on Computing in High Energy Physics, Oxford, April 1989 (1989); H. Johnstad, "PAW at Fermilab: Core Based Graphics Implementation of HIGZ," FERMILAB-CONF-89/142 (1989) and Proceedings of the Conference on Computing in High Energy Physics, Oxford, April 1989 (1989); R. Bock, R. Brun, O. Couet, J.C. Marin, R. Nierlıaus, L. Pape, N. Saumon, C. Vandoni and P. Zanarini "PAW: Towards a Physics Analysis Workstation," CERN-DD/87/5 (1987), Published in Asilomar Computing II. E. Phys. 1987:181.

PYTHIA, H.-U. Bengtsson and T. Sjöstrand, "The LUND Monte Carlo for Hadronic Processes: PYTHIA Version 4.8," Lund University Report LU-TP-87-3 (1987), Published in Comput. Phys. Comm. 46 (1987) 43; see also H.-U. Bengtsson and T. Sjöstrand, "PYTHIA: The LUND Monte Carlo for Hadronic Processes," Lund University Report LU-TP-86-17, Published in UCLA SSC Workshup. 1986:228 and also in Snowmass Summer Study 1986:311.

RABHAT, K. Tobimatsu, Y. Shimizu, "Radiative Bhabha Scattering in Special Configurations with Missing Final $e^{+}$and/or $e^{-}$, " KEK-Preprint-89-9 '1989), suhmitted to Comp. Phys. Commun. 
REASON, "The REASON Project," W.B. Atwood, R. Blankenbecler, P. F. Kunz, B. Mours, A. Weir and G. Word, SLAC-PUB-5242 (1990).

SAGE, R. Chaffee, "A User's Guide for SAGE: A General System for Monte Carlo Event Generation with Preferred Phase Space Density Distributicns," SLAC Report CGTM-195 (1979).

SIGMA, C. Vandoni, "SIGM A - System for Interactive Graphical Mathematical Applications," CERN Program Library Q122 (1988).

SPIRES, A. Rittenberg, F.E. Armstrong, B.S. Levine, T.G. Trippe, C.G. Wohl and G.P. Yost, "A User's Guide to Particle Physics Computer Searchable Data Bases on The SLAC SPIRES System," Lawrence Berkeley Laboratory Report LBL-19173 (1986); see also L. Addis, "SPIRES I Online Search Guide," SLAC Report SLAC-TN-75-015 (1975).

TEEGG, D. Karlen, "Radiative Bhabha Scattering for Singly Tagged and Untagged Cunfigurations," SLACPUB-4121-Rev. (1987), published in Nucl. Phys. B289 (1987) 23; see also CERN Yellow Report 89-08, vol. 3 (1989) p. 95.

TIPTOP, S. Jadach and J. Kühn, "The Monte Carlo Program TIPTOP for Heavy Fermion Production and Decay at LEP and SLC," Max Planck Institute Report. MPI.PAE/PThr-86/64 (1986); see also S. Jadach and J. H. Kühn, "Asymmetries in Heavy Fermion Production and Decay," Max Planck Institute Report MPI-PAE/PTh 79/86 (1986), published in Phys. Lett. 191B (1987) 313; and CERN Yellow Report 89-08, vol. 3 (1989) p. 293.

TOOLPACK, W. R. Cowell, "User's Guide to TOOLPACK/1 Tools for Data Dependency Analysis and Program Transformation," Argonne National Laboratory Report ANL-88-17 (1988); see also W. R. Cowell, S.J, Hague and R.M.J. Iles "TOOLPACK/1 Release 2: Introductory Guide, Second Erition Octcber 1986," Argonne National Laboratory Report ANL-86-43 (1987).

TYPES, S. Youssef, "The TYPES Users Guide: A Data Abstraction Package in FORTRAN: Version 1.0," Florida State University Supercomputer Computations Research Institute Report FSU.SCRI-90T. 03 (1000).

UCLA, see, for example, C. D. Buchanan and S. Chun, "Evidence Indicating that Meson and Baryon Formation are Controlled by Phase Space and a Linear Confining Quark Potential," UCLA-JIEP. 89-003 (1989).

UGS, R. C. Beach, "The Unified Graphics System for FORTRAN 77: Internal Operation and Maintenance Manual, Revised Version," SLAC Report CGTM-205 (1988); see also R. C. Beach, "The Unified Graphics System for FORTRAN 77: Graphic Algorithms Manual, Revised version," SLAC Report CGTM-204-Rev.3 (1988); R. C. Beach, "The Unified Graphics System for FORTRAN 77: Programming Manual, Revised version," SLAC Report CGTM-203-Rev.3 (1988); R. C. Beach, "Converting from the FORTRAN-66 Version of the Unified Graphics System to the FORTRAN-77 Version," SLAC Report CGTM-2I1 (1984); R. C. Beach, "A Version of the SIAC Unified Graphics System Coded Almost Entirely in FORTRAN," SLAC Report CGTM-191 (1978); and R. C. Beach, "An Introduction to the SLAC Unified Graphics System," SLAC Report CGTM-166 (1975). 
VENUS, see, for example, K. Werner, "A New String Model (VENUS 2) for Hadronic Collisions Based on Color Exchange Between Quarks and Anti-Quarks," Brookhaven National Laboratory Repor BNL-42032 (1989), Published in Moriond 1989: Hadronic:515; K. Werner, "Energy and Particle Densities In Ultrarelativistic Heavy Ion Collisions from the String Model VENUS," Brookhaven National Laboratory Report BNL-42162 (1988), Published in Phys. Lett. B219 (1989) 111; K. Werner, "Multiparticle Production in $p-p, p-A r$ and $p-X e$ Collisions at $200 \mathrm{GeV}$ by the Multist.ring Model VENUS," Brookhaven National Laboratory Report BNL-41500 (19.83), Published in Plys. Rev. D39 (1989) 780; K. Werner, "Analysis of Energy Flow in $O^{16}-n u c t e u s$ Collisions at $60 \mathrm{GeV}$ and $200 \mathrm{GeV}$ by the Multistring Model VENUS," Brookhaven National Laboratory Report BNL 41501 (1988), Published in Z. Phys. C42 (1989) 85: and K. Werner, "Analysis of p- zucleus and nucleus-nucleus Scaltering at $200 \mathrm{GeV}$ by the Multistring Model VENUS," Brookhaven Natıonal Laboratory Report BNL-40981 (1988), published in Phys. Lett. 208B (1988) 520.

YFS2, S. Jadach and B.F.L. Ward, "Exclusive Exponentiation in the Monte Carlo Yennie-Frautschi-Suura Approach," Krakow University Preprint TPJU-89-19 and University of Tenressee Preprint UTHEP89-0703 (1989); see itso Stanislaw Jadach and B.F.L. Ward "The Exclusive Exponentiation in the Monte Carlo: The Case of the Initial State Bremsstrahlung," CERN-TH-5399/89 (1989); and Stanislaw Jadach, "Yennic-Frautschi-Suura Soft Photons in Monte Carlo Event Generators," MP]PAE/PTh 6/87 (1987).

ZEBRA, R. Brun and J. Zoll, "ZEBliA - Data Structure Managenent System," CERN Program Library Q100 (1989). 